\title{
Updated Requirements for Measurement Quality and Quality Assurance of Point-Of-Care Testing (POCT) - Blood Glucose Measurement Systems with Unit-Use Reagents Suitable for the Initial Diagnosis of Diabetes Manifested in Pregnancy or Gestational Diabetes Mellitus (GDM) According to the GDM Guideline of the German Diabetes Association (DDG)
}

\section{Consensus Recommendation by the German United Society for Clinical Chemistry and Laboratory Medicine (DGKL) and the German Diabetes Association 2015}

Authors

Affiliations
M. Neumaier ${ }^{1}$, P. B. Luppa ${ }^{2}$, T. Koschinsky ${ }^{3}$, E. Siegel ${ }^{4}$, G. Freckmann ${ }^{5}$, L. Heinemann ${ }^{5}$

President of DGKL

Chairman POCT-working group of DGKL

POCT-working group of DGKL and DDG

${ }^{4}$ President of DDC

Working Group Diabetes Technology of DDG

\section{Bibliography}

Dol http://dx.doi.org/ 10.1055/s-0035-1553622 Diabetologie 2015; 10: 1-3 (C) Georg Thieme Verlag KG Stuttgart · New York . ISSN 1861-9002

\section{Correspondence}

Prof. Dr. T. Koschinsky

POCT-AG und DDG

München

tkoschinsky@t-online.de

\section{Basics and Requirements $\nabla$}

In 2011, the German Diabetes Association (DDG) and the German Society of Obstetrics and Gynecology (DGGG) published a new, inter-disciplinary, evidence-based S3-guideline (AWMF guideline 057/008) for gestational diabetes mellitus (GDM, ICD-10: 024.4G) [1]. It contains recommendations on the diagnostic procedure, treatment and follow-up care of GDM. This guideline also makes it possible for the first time for the attending physician to use POCT glucose measurement systems with unit-use reagents in the initial diagnostic procedure of GDM. At the same time, a corresponding manufacturer's recommendation is a requirement for this use $[1,2]$ : "For the initial diagnostic procedure of diabetes manifested in pregnancy or gestational diabetes when using unit-use reagents and related measurement systems, these systems are explicitly intended for physician use in the diagnostic procedure according to the manufacturer's recommendations (instructions for use)."

A common premise of this guideline and other relevant DDG guidelines [1-3] is that handheld instruments for blood glucose (BG) selfmeasurement (homecare sector) are not suitable for initial diagnostic procedure of GDM or any other form of diabetes. All relevant guidelines reject the use of "patient measurement systems" since these systems have to comply only with the minimum requirements according to the corresponding ISO standard 15197 in the case of their European approval with a CE mark. For these systems, the quality of the glucose measurements within the clinically relevant measurement range may deviate from the reference value by up to $\pm 20 \%$ for $95 \%$ of all values until May 2016, the revised standard, starting from June 2016 , restricts the deviation to $\pm 15 \%$. This is unacceptable as the maximum permissible meas- urement error for the diagnostic procedure of GDM.

The topicality and practical relevance of the new GDMGuideline are reflected by the fact that its essential content has also been adopted in the decision by the Federal Joint Committee in its session on 15 December 2011, to supplement the guidelines concerning medical care during pregnancy and after childbirth (motherhood guidelines) accordingly [4].

Since the above-mentioned DDG guidelines [1 3] contained no detailed specifications for the required manufacturer's recommendations, the requirements for the measurement quality and the quality assurance of POCT glucose measurement systems for the initial diagnostic procedure of GDM were fully detailed in 2012 in a joint statement by the German United Society for Clinical Chemistry and Laboratory Medicine (DGKL) and the DDG, taking into consideration the technical possibilities available at that time [5].

Because the measurement quality of the best available POCT glucose measurement systems with unit-use reagents [6-11] has since been further substantially improved, it is possible (and we see the need for it) for DGKL and DDG to jointly update the existing requirement especially in terms of the measuring quality in the diagnostic procedure of overt diabetes in pregnancy or GDM ( $\bullet$ Table 1).

That should serve as an evidence-based guideline for the manufacturers, the approval and regulatory authorities, the users in clinical trials and in routine practice, as well as the third-party payers. 
Table 1 Comparison of the minimum requirements for the measurement quality and quality assurance (QA) of POCT glucose measurement systems with unituse reagents for the diagnostic procedure of GDM as recommended by the DGKL and DDG (2012 and 2015).

\begin{tabular}{|c|c|c|}
\hline & 2012 & 2015 \\
\hline approval criteria & Conformité Européene: CE mark & Conformité Européene: CE mark \\
\hline test sample & venous whole blood (rather than capillary blood) & venous whole blood (rather than capillary blood) \\
\hline $\begin{array}{l}\text { system accuracy according to test standard } \\
\text { with the following modifications: } \\
\text { blood glucose concentration } \\
\text { tolerance range } \\
\text { minimum requirements } \\
\text { manufacturer warranty of these modifications } \\
\text { even after approval }\end{array}$ & $\begin{array}{l}\text { DIN EN ISO } 15197: 2003 \\
<75 \mathrm{mg} / \mathrm{dL} \quad>75 \mathrm{mg} / \mathrm{dL} \\
\pm 10 \mathrm{mg} / \mathrm{dL} \quad \pm 15 \% \\
95 \% \text { of all measured values in the tolerance range } \\
\text { for each new lot of test strips with product- } \\
\text { specific testing procedures by the manufacturer }\end{array}$ & $\begin{array}{l}\text { DIN EN ISO } 15197: 2013 \\
<100 \mathrm{mg} / \mathrm{dL} \quad>100 \mathrm{mg} / \mathrm{dL} \\
\pm 10 \mathrm{mg} / \mathrm{dL} \quad \pm 10 \% \\
95 \% \text { of all measured values in the tolerance range } \\
\text { for each new lot of test strips with product- } \\
\text { specific testing procedures by the manufacturer } \\
\text { in the case of unacceptable external QA, the } \\
\text { manufacturer is obliged to produce evidence of } \\
\text { the outcome of its relevant testing procedure } \\
\text { upon request of the regulatory authority. }\end{array}$ \\
\hline $\begin{array}{l}\text { ensuring the measuring quality according to } C E \\
\text { Internal quality assurance (QA) } \\
\text { external QA (modified) }\end{array}$ & $\begin{array}{l}\text { RiliBAEK } 2008 \\
1 \times / \text { week } \\
\text { mandatory participation at the level of office- } \\
\text { based physicians as well }\end{array}$ & $\begin{array}{l}\text { RiliBAEK } 2014 \\
\text { modified: on all measurement days } \\
\text { mandatory participation at the level of office- } \\
\text { based physicians as well }\end{array}$ \\
\hline
\end{tabular}

\section{Updating the requirements for the measuring quality and the quality assurance of the POCT glucose meas- urement systems with unit-use reagents for the diag- nostic procedure of overt diabetes in pregnancy or GDM (2015) \\ $\checkmark$}

1. Eligibility criteria for the CE mark: As in the past, with a focus on the diagnostic procedure of overt diabetes in pregnancy or GDM.

2. Test sample: only venous whole blood, no capillary blood!

3. Proof of accuracy across the clinically-relevant measurement range:

3.1 In the case of approval of the meter and test strip sensor in Germany/EU in accordance with DINEN ISO 15197:2013 with the following modification: At least $95 \%$ of individual blood glucose (BG) readings should be within $\pm 10 \mathrm{mg} / \mathrm{dL}$ compared to the measured values with the manufacturer's reference system (hexokinase method or GOD method with the YSI system) at BG concentrations of $<100 \mathrm{mg} / \mathrm{dL}$, and within $\pm 10 \%$ compared to the above-mentioned reference system at BG concentrations of $\geq 100 \mathrm{mg} / \mathrm{dL}$.

3.2 In the case of production of new lots of test strips/sensors post-approval: The manufacturer should ensure that each new batch that is placed on the market complies with the requirements according to 3.1. The suitable test method can be determined by the manufacturer in a product-specific manner. If the in-use measurement quality of new batches cannot be secured in accordance with 4 , the manufacturer is obliged to provide evidence of the outcome of his relevant procedure according to 3 upon request of the regulatory authority.

4. Ensuring the in-use measurement quality:

4.1 Provisions of RiliBAEK (Revised Guideline of the German Medical Association on Quality Assurance in Medical Laboratory Examinations)[12, 13]: All applicable requirements of RiliBAEK for the POCT systems with unit-use reagents should be observed, including the rules for the internal and external quality assurance (QA). The internal QA is done by single control sample measurement. At least two different glucose concentrations are to be used as controls, insofar as a respective second control solution is available. The maximum permissible deviation of the control value from the target value is $11 \%$ in the range of validity of 40 $400 \mathrm{mg} / \mathrm{dL}$. When using a POCT system with unit-use reagents on several measurement days/week, the internal QA takes place on all measurement days instead of once a week (minimum requirement of RiliBÄK).

In external $\mathrm{QA}$, the maximum permissible deviation in the legally required ring trials by the German Ring Trial National Reference Laboratories ("Reference Institute for Bioanalytics" and "INSTAND") is $15 \%$ for each glucose measurement method in the laboratory as well as in the POCT area.

However, in the case of the above mentioned POCT glucose measurement systems, the RiliBAEK special regulations on the use of control samples with method-specific target values currently still need to be followed rather than the reference method value due to the lack of suitable whole blood samples, which does not allow for any conclusions regarding the accuracy of the POCT glucose measurement devices. Therefore, in this situation there is a legitimate need for manufacturers, the German Ring Trial National Reference Laboratories and control material manufacturer to look for and provide a suitable control sample material. [14]. The use of the so-called "consensus value" has been a practical solution so far [14], as it has been tested by the two Ring Trial National Reference Laboratories for comparative evaluation.

4.2 Additional regulation of the GDMGuideline of DDG and DGGG [1, 2]: At the level of the office-based physicians, participation in the external quality assurance is reqired also for the POCT glucose measurement systems with unit-use reagents, analogously to the RiliBAEK regulation.

Conflict of Interest: The corresponding author and the co-authors declare no business or personal affiliations with respect to this manuscript in the past 3 years.

\section{References}

1 Kleinwechter H, Schäfer-GrafU, Bührer C et al. Gestationsdiabetes mellitus (GDM). Evidenzbasierte Leitlinie zu Diagnostik, Therapie und Nachsorge der DDG und der DGGG. Diabetologie Stoffw 2011; 6: $290-328$

2 Kleinwechter H, Schäfer-Graf U, Bührer C et al. Gestationsdiabetes mellitus (GDM) - Diagnostik, Therapie und Nachsorge. Diabetologie Stoffw 2014; 9 (Suppl 2): S202-S213 in: Praxisempfehlungen der Deutschen Diabetes-Gesellschaft, Aktualisierte Version 2014, Kellerer 
M, Siegel E (Hrsg.) sowie im Internet: „Aktuelle Fassung der evidenzbasierten Leitlinien“" www.deutsche-diabetes-gesellschaft.de

3 Kerner W, Brückel J. Definition, Klassifikation und Diagnostik des Diabetes mellitus. Diabetologie Stoffw 2014; 9 (Suppl 2): S96-S99 in: Praxisempfehlungen der Deutschen Diabetes-Gesellschaft, Aktualisierte Version 2014, Kellerer M, Siegel E (Hrsg) sowie im Internet: „Aktuelle Fassung der evidenzbasierten Leitlinien“" www.deutsche- diabetes-gesellschaft.de

4 Beschluss des Gemeinsamen Bundesausschusses zum Screening auf Gestationsdiabetes mellitus im Internet: G-BA_Beschluss_2011-1215_Mu-RL_Screening_GDM.pdf

5 Thiery J, Luppa PB, Koschinsky T et al. Anforderungen an die Messqualität und Qualitätssicherung (QS) von Point-of-Care-Testing (POCT)Blutglukose-Messsystemen, die für das Screening und die Diagnose eines Gestationsdiabetes mellitus (GDM) gemäß der GDM-Leitlinie der Deutschen Diabetes-Gesellschaft (DDG) geeignet sind: Eine Initiative der POCT-AG der Deutschen Vereinten Gesellschaft für Klinische Chemie und Laboratoriumsmedizin in Abstimmung mit der DDG Dezember 2012. Diabetologie Stoffw 2013; 8: 195-197

6 Freckmann G, Baumstark A, Schmid C et al. Evaluation of 12 blood glucose monitoring systems for self-testing: System accuracy and measurement reproducibility. Diabetes Technol Ther 2014; 16: 113-122

7 Klaff LJ, Brazg R, Hughes $K$ et al. Accuracy evaluation of Contour Next compared with five blood glucose monitoring systems across a wide range of blood glucose concentrations occurring in a clinical research setting. Diabetes Technol Ther 2014; 17: 8-15
8 Pleus S, Schmid C, Link $M$ et al. Accuracy assessment of two novel systems for self-monitoring of blood glucose following ISO 15197:2013. J Diabetes Sci Technol 2014; 8: 906-908

9 Freckmann G, Schmid C, Pleus $S$ et al. System accuracy evaluation of systems for point-of-care testing of blood glucose: a comparison of a patient-use system with six professional-use systems. Clin Chem Lab Med 2014; 52: 1079-1086

10 Halldorsdottir S, Warchal-Windham ME, Wallace JF et al. Accuracy evaluation of five blood glucose monitoring systems: the North American comparator trial. J Diabetes Sci Technol 2013; 7: 1294-1304

11 Freckmann G, Pleus S, Link $M$ et al. Accuracy evaluation of four blood glucose monitoring systems in unaltered blood samples in the low glycemic range and blood samples in the concentration range defined by ISO-15197. Diabetes Technol Ther 2015, [Epub ahead of print] PMID: 25901021

12 Bundesärztekammer. Richtlinie der Bundesärztekammer zur Qualitätssicherung laboratoriumsmedizinischer Untersuchungen (RiliBÄK 2014). Dtsch Ärztebl 2014; 111: A1583-A1618

13 German Medical Association. Revision of the "Guideline of the German Medical Association on Quality Assurance in Medical Laboratory Examinations - RiliBAEK". J Lab Med 2015; 39 (1): 26-69

14 Petersmann A, Luppa P, Michelsen A et al. Gemeinsame Stellungnahme zur Situation der Bewertung von Ringversuchen für Glukose mittels Systemen für die patientennahe Sofortdiagnostik (POCT). J Lab Med 2012; 36: $165-168$ 